\title{
Open vs laparoscopic hernia repair in the Brazilian Public Health System. An 11-year nationwide population-based study
}

\author{
Eduardo Morais EVERLING'1 ${ }^{1}$ Daniela Santos BANDEIRA ${ }^{1}$, Felipe Melloto GALLOTTI1,2, \\ Priscila BOSSARDI ${ }^{3}$, Antoninho José TONATTO-FILHO ${ }^{1,4}$ and Tomaz de Jesus Maria GREZZANA-FILHO ${ }^{1,5}$
}

Received: 23 July 2020

Accepted: 29 July 2020

\begin{abstract}
Background - Abdominal wall hernia is one of the most common surgical pathologies. The advent of minimally invasive surgery raised questions about the best technique to be applied, considering the possibility of reducing postoperative pain, a lower rate of complications, and early return to usual activities. Objective - To evaluate the frequency of open and laparoscopic hernioplasties in Brazil from 2008 to 2018, analyzing the rates of urgent and elective surgeries, mortality, costs, and the impact of laparoscopic surgical training on the public health system. Methods - Nationwide data from 2008 to 2018 were obtained from the public health registry database (DATASUS) for a descriptive analysis of the selected data and parameters. Results - 2,671,347 hernioplasties were performed in the period, an average of 242,850 surgeries per year ( $99.4 \%$ open, $0.6 \%$ laparoscopic). The economically active population (aged 20-59) constituted the dominant group (54.5\%). There was a significant reduction $(P<0.01)$ in open surgeries, without a compensatory increase in laparoscopic procedures. $22.3 \%$ of surgeries were urgent, with a significant increase in mortality when compared to elective surgeries $(P<0.01)$. The distribution of laparoscopic surgery varied widely, directly associated with the number of digestive surgeons. Conclusion - This study presents nationwide data on hernia repair surgeries in Brazil for the first time. Minimally invasive techniques represent a minor portion of hernioplasties. Urgent surgeries represent a high percentage when compared to other countries, with increased mortality. The data reinforce the need for improvement in the offer of services, specialized training, and equalization in the distribution of procedures in all regions.
\end{abstract}

HEADINGS - Hernia. Herniorrhaphy, methods. Laparoscopy. Population studies in public health.

\section{INTRODUCTION}

Abdominal wall hernias are pathologies widely observed in clinical practice ${ }^{(1,2)}$. It is estimated that the incidence in Brazil is around 290 thousand cases per year, with $54 \%$ found in the inguinal region $^{(3)}$. Most of the time, hernias occur due to the weakening of the abdominal wall. Nonetheless, there is also an association with congenital anomalies, hereditary defects in collagen synthesis or renewal, and increased intra-abdominal pressure ${ }^{(4)}$. Also, a significant number of hernias (between 10 and $15 \%$ ) occur in the healing area of any type of previous open abdominal surgery - identified as incisional hernias ${ }^{(5)}$. Risk factors such as smoking, type II diabetes mellitus, obesity, chronic obstructive pulmonary disease, cirrhosis, and prostatic diseases can have a negative impact, increasing the chance of postoperative complications and recurrences ${ }^{(6-8)}$. Most of the time, surgical correction is carried out in an elective and programmed way. However, the occurrence of incarceration and strangulation of the hernia content requires urgent correction, with significantly associated morbidity. In the last decades, there have been surgical advances in various techniques and the spread of the use of inorganic meshes, which has considerably reduced rate of recurrences ${ }^{(9)}$. Recently, the introduction of techniques by laparoscopy increased the therapeutic arsenal and raised questions about the best technique to be applied, considering the possibility of reducing postoperative pain, a lower rate of surgical complications, and early return to usual activities ${ }^{(10,11)}$. Thus, the impact of these pathologies in terms of physical suffering, the number of workdays lost, disabilities, and costs for a public health system is highly relevant. The objective of this work is to evaluate the frequencies of open vs laparoscopic hernia repair surgeries in Brazil, in all states, and also in their macroregions between the years 2008 and 2018, to descriptively analyze the rates of urgent and elective surgeries, mortality, costs, and the impact of training in laparoscopic surgery on the public health system.

\section{METHODS}

A cross-sectional study was carried out with an analysis of prevalence between January 2008 and December 2018. The data were extracted from DATASUS (Brazilian public health registry database) ${ }^{(12)}$. The associated hospitals that are part of the Unified Health System (SUS) issue a Hospitalization Authorization, which identifies the procedure performed, the proposed treatment, and the payment that will be made later by the government to the af-

Declared conflict of interest of all authors: none

Disclosure of funding: no funding received

${ }^{1}$ Hospital Nossa Senhora da Conceição (HNSC), Departamento de Cirurgia Geral, Porto Alegre, RS, Brasil. ${ }^{2}$ Hospital Nossa Senhora das Graças, Unidade de Cirurgia do Aparelho Digestivo, Curitiba, PR, Brasil. ${ }^{3}$ Hospital Santa Casa de Misericórdia de Curitiba, Unidade de Dermatologia, Curitiba, PR, Brasil. ${ }^{4}$ Hospital de Clínicas de Curitiba, Unidade de Cirurgia Plástica, Curitiba,

PR, Brasil. ${ }^{5}$ Hospital de Clínicas de Porto Alegre (HCPA), Unidade de Cirurgia do Fígado e Transplantes, Porto Alegre, RS, Brasil.

Corresponding author: Eduardo Morais Everling. E-mail: edueverling@gmail.com 
filiated Institutions. The data are related to open and laparoscopic inguinocrural, umbilical, epigastric, and incisional hernias. A subanalysis of strangulated hernioplasties, with and without intestinal resection, was included in the study.

The comparison of unpaired categorical variables, such as mortality rates, was performed using Pearson's chi-square test. The bivariate correlation between the analyzed year and the number of hernioplasties was performed using Pearson's correlation coefficient. Statistical analyzes were carried out with the PEPI software for Windows, version 11.65, and IBM SPSS Statistics, version 22.0.

\section{RESULTS}

Two million nine hundred thirty-four thousand seven hundred sixty $(2,934,760)$ hernias were reported by the system over 11 years, an average of 266,796 per year. Of these, $53.9 \%$ were inguinal hernias. The rest, $46.1 \%$, included the other hernias. The distribution of these notifications, along with the characteristics of gender, age group, and ethnicity, are shown in TABLE 1.

TABLE 1. Notification of hernias in Brazil between 2008 and 2018. Demographic characteristics.

\begin{tabular}{|c|c|c|c|}
\hline & & $\begin{array}{c}\text { Inguinal hernia } \\
(\mathrm{n}=1,581,303)\end{array}$ & $\begin{array}{l}\text { Other hernias } \\
(\mathrm{n}=1,353,457)\end{array}$ \\
\hline \multirow{2}{*}{ Gender } & Male & $1,314,620(83.1 \%)$ & $658,684(48.7 \%)$ \\
\hline & Female & $266,683(16.9 \%)$ & $694,773(51.3 \%)$ \\
\hline \multirow{6}{*}{$\begin{array}{l}\text { Age } \\
\text { group }\end{array}$} & Under 1 year & $57,370(3.6 \%)$ & $16,222(1.2 \%)$ \\
\hline & 1 to 4 years & $132,330(8.4 \%)$ & $117,842(8.7 \%)$ \\
\hline & 5 to 14 years & $141,600(9.0 \%)$ & $137,870(10.2 \%)$ \\
\hline & $\begin{array}{l}15 \text { to } 19 \text { years } \\
\text { old }\end{array}$ & $34,581(2.2 \%)$ & $26,983(2.0 \%)$ \\
\hline & $\begin{array}{l}20 \text { to } 59 \text { years } \\
\text { old }\end{array}$ & $777,287(49.1 \%)$ & $822,975(60.8 \%)$ \\
\hline & $\begin{array}{l}60 \text { years or } \\
\text { older }\end{array}$ & $438,135(27.7 \%)$ & $231,565(17.1 \%)$ \\
\hline \multirow{6}{*}{ Ethnicity } & White & $518,251(32.8 \%)$ & $407,368(30.1 \%)$ \\
\hline & Brown & $520,509(32.9 \%)$ & $466,865(34.5 \%)$ \\
\hline & Black & $44,582(2.8 \%)$ & $44,566(3.3 \%)$ \\
\hline & Yellow & $14,532(0.9 \%)$ & $14,300(1.0 \%)$ \\
\hline & Indigenous & $1,450(0.1 \%)$ & $1,315(0.1 \%)$ \\
\hline & $\begin{array}{c}\text { No } \\
\text { information }\end{array}$ & $481,979(30.5 \%)$ & $419,043(31.0 \%)$ \\
\hline
\end{tabular}

In the referred period, 2,671,347 hernioplasties were carried out, an average of 242,850 surgeries per year, of which $2,656,438$ $(99.4 \%)$ were open and 14,909 (0.6\%) were laparoscopic. The distribution by type of hernioplasty, surgical technique (whether open or laparoscopic), urgent or elective repair, and the frequencies in relation to the total is shown in FIGURE 1. It was observed that the total number of urgent surgeries was 596,307, an average of $22.3 \%$, while elective hernioplasties corresponded to $77.7 \%$ of the total, with 2,075,040 procedures in the period. When analyzing only videolaparoscopic surgeries (VLP), the percentage of urgent surgeries was $34 \%$, with a predominance of inguinal hernioplasty, with $58 \%$ of cases.

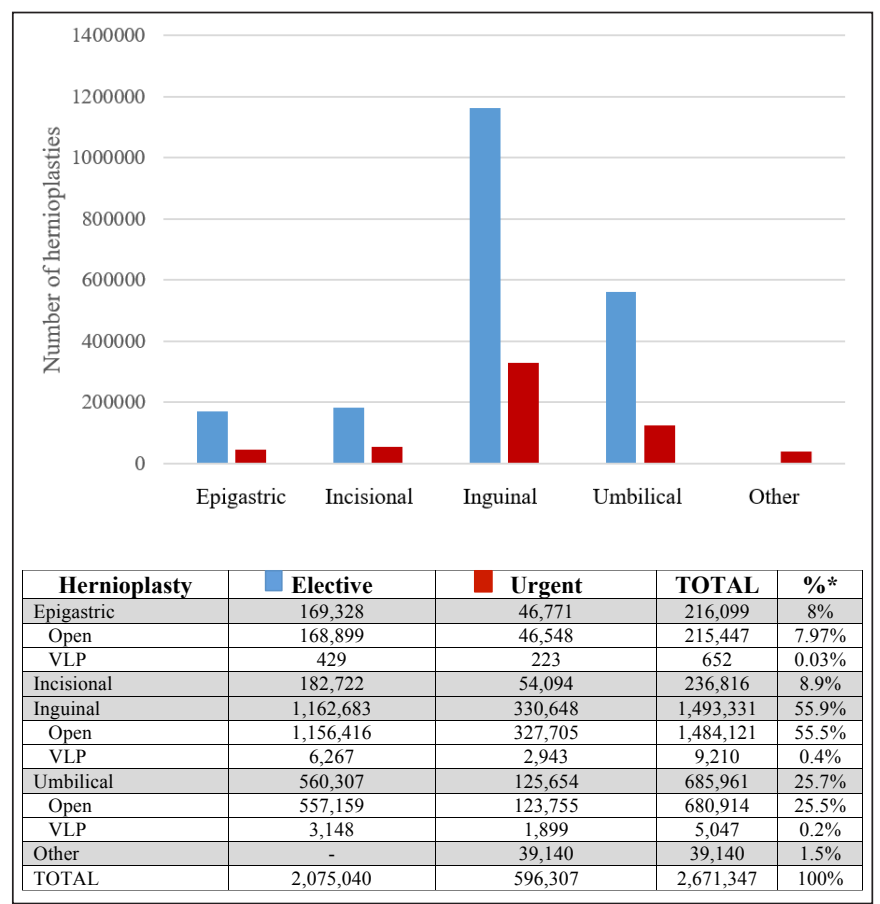

FIGURE 1. Hernioplasties performed in the Brazilian Unified Health System in the 2008-2018 period. The percentages refer to the total number of hernioplasties performed in the period evaluated. Between 2008 and 2018, the average number of urgent surgeries was $22.3 \%$, distributed as follows: $21.6 \%$ of epigastric hernioplasties, $22.8 \%$ of incisional hernioplasties, $22.1 \%$ of inguinal hernioplasties, and $18.3 \%$ of umbilical hernioplasties.

The analysis of hernioplasties year by year in the period evaluated is shown in FIGURE 2. Pearson's correlation test was performed to determine the association of the year analyzed with the number of hernioplasties performed, observing a trend towards an increase in VLP inguinal hernioplasties each year, with a moderately positive correlation $(\mathrm{r}=0.62, P=0.042)$. At the same time, there was no significant change in the number of umbilical and epigastric VLP hernioplasties in the period ( $\mathrm{r}=0.06, P=0.846$ and $\mathrm{r}=0.09, P=0.77$, respectively). The test showed a strong negative correlation between the period analyzed and the number of inguinal and open epigastric hernioplasties, with a significant reduction in the number of procedures over time $(r=-0.79, P<0.01$ and $\mathrm{r}=$ $-0.76, P=0.01$, respectively). Open umbilical hernioplasty, on the other hand, showed a significant increase over the period analyzed $(\mathrm{r}=0.70, P=0.016)$.

As for the regional distribution, most hernioplasties were performed in the Southeast $(37.5 \%)$, followed by the Northeast (33.4\%) and South (15.1\%). The North and Center-West regions were responsible for only $7.7 \%$ and $6.1 \%$ of the procedures performed in the period, respectively. The distribution, according to the population of each federative unit and Brazilian region, on the scale per 100,000 inhabitants, shows a different scenario, represented in FIGURE 3.

There were 3,845 deaths in the period evaluated, 31 of which were in hospitalizations for laparoscopic hernioplasty. When mortality rates between open and videolaparoscopic hernioplasties were compared, there was a significant increase in mortality in the laparoscopic repair technique for epigastric and umbilical hernias, with rates of $0.61 \%$ vs $0.13 \%$ and $0.26 \%$ vs $0.09 \%$, re- 

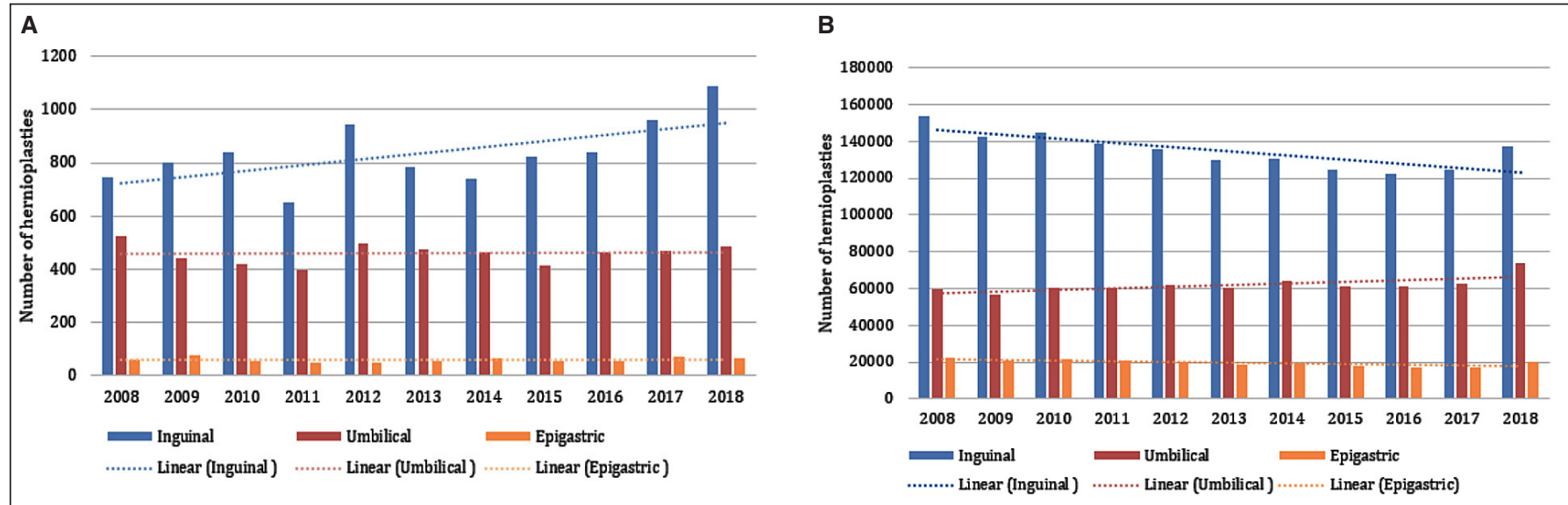

FIGURE 2. Hernioplasties in the SUS from 2008-2018. The dotted lines represent the trend of evolution of the number of hernioplasties in the analyzed period. A) Videolaparoscopic hernioplasties in SUS from 2008-2018. An average of 837 VLP inguinal hernioplasties (ranging from 650-1,085), 459 (395-525) VLP umbilical hernioplasties, and 59 (50-77) VLP epigastric hernioplasties were performed annually. B) Open hernioplasties in SUS from 2008-2018. On average, 134,933 (122,266-153,266) open inguinal hernioplasties, 61,863 (56,338-73,660) open umbilical hernioplasties, and 19,587 $(16,0806-22,168)$ open epigastric hernioplasties were performed annually.

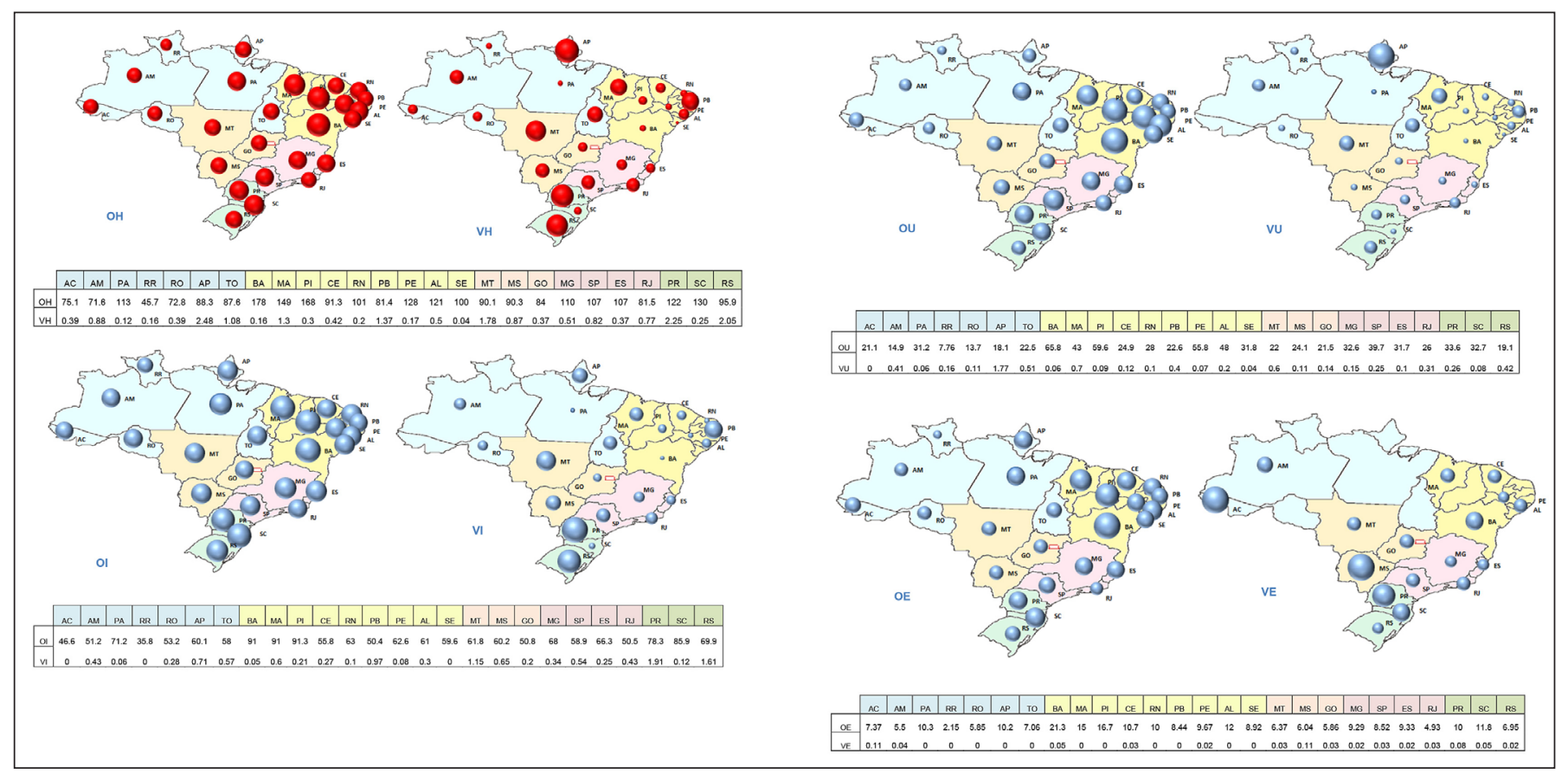

FIGURE 3. Geographic distribution of hernioplasties performed in 2018 in Brazil, by federative unit, per 100,000 inhabitants. OH: open hernioplasties; VH: videolaparoscopic hernioplasties; OE: open epigastric; VE: videolaparoscopic epigastric; OU: open umbilical; VU: videolaparoscopic umbilical; OI: open inguinal; VI: videolaparoscopic inguinal.

spectively $(P=0.001$ and $P<0.001)$. The difference also occurred in inguinal hernias, although more discreetly $(0.15 \%$ vs $0.09 \%$, $P=0.04)$. When the urgent and elective procedures were stratified, there was a significant difference in mortality between open and laparoscopic techniques in urgent epigastric hernioplasties and elective inguinal hernioplasties, as shown in FIGURE 4. Strangulated hernias showed a significant increase in mortality in cases involving intestinal resection compared to hernioplasties without intestinal resection $(4.63 \%$ vs $1.41 \%, P<0.001)$.

Regarding the cost of hospitalizations, open hernioplasties presented an average transfer of $\mathrm{R} \$ 552.65$ per hospitalization. VLP hernioplasties, on the other hand, presented an average transfer of $\mathrm{R} \$ 430.33$ in the same period. One of the justifications for the cost disparity is the difference in transfer to hospitals according to the procedure performed ${ }^{(13)}$. According to the SUS table, the transfer for VLP epigastric hernioplasty is $35 \%$ lower than that of open epigastric hernia repair (difference of approximately $R \$ 200.00$ ). The transfer for VLP inguinal hernioplasty and VLP umbilical hernia is 15 to $17 \%$ lower than the corresponding open procedures (difference of $\mathrm{R} \$ 68.60$ and $\mathrm{R} \$ 74.33$, respectively). 


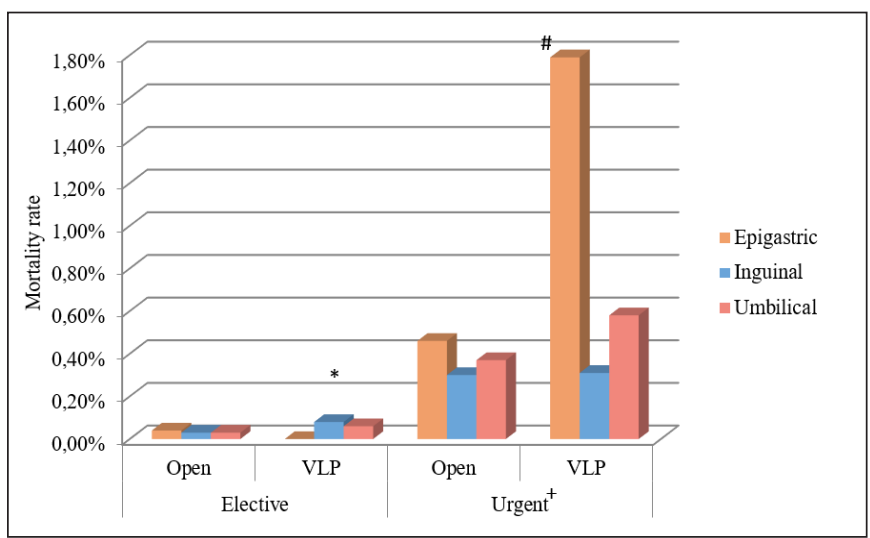

FIGURE 4. Mortality rates according to the type of hernioplasty and the character of the procedure between 2008 and 2018. There was a significant difference between urgent and elective hernioplasties $+(0.51 \%$ vs $0.04 \%$, $P<0.001)$, urgent open and laparoscopic epigastric hernioplasties\# $(1.79 \%$ vs $0.46 \%, P=0.003$ ), and elective open and videolaparoscopic inguinal hernioplasties* $(0.08 \%$ vs $0.03 \%, P=0.016)$.

The association between laparoscopic hernioplasty performed in each Brazilian region and the number of digestive surgeons in 2018 is shown in FIGURE 5.

\section{DISCUSSION}

Hernias are considered preventable causes of death. According to some population studies, it is estimated that the prevalence of hernias in the population is in the range of $5-10 \%{ }^{(14)}$. Apparently, the risk of a patient having an inguinal or femoral hernia during life is around $25 \%$ for men and $3 \%$ for women ${ }^{(15,16)}$. There is no consensus on the best surgical treatment for abdominal hernias. Surgical management has evolved over time, and studies have shown comparable results between laparoscopic and open techniques. However, it is common sense that minimally invasive surgery has advantages with regard to managing postoperative pain and returning to activities more quickly ${ }^{(10,11,17)}$. Some authors suggest that inguinal hernioplasty could be an indicator of the surgical quality offered by different institutions and countries, thus establishing a scientific basis for the critical evaluation of the procedure and the improvement of health systems ${ }^{(18)}$.

This study is the first to report hernia surgeries with population data from the Brazilian public health system. The recording of such data involves significant effort and costs. Although the data do not present in-depth clinical characteristics of the patients, some indicators could be extracted with detailed information and reliability, which is crucial to evaluate clinical results. This is a recurring problem in many countries, which is why there is a scarcity of studies worldwide that evaluate the methods and results of the treatment of abdominal hernias on a large scale ${ }^{(18,19)}$. To our knowledge, this is the study that evaluates the most significant number of patients in the most prolonged period, correlating the data with mortality, surgical techniques, and training of surgeons.

Our series demonstrated the predominance of males in inguinal hernias, similar to those found in other large-scale studies ${ }^{(20)}$. In the other hernias, the distribution showed a slight predominance of females. It was observed that the age groups of the economically active population ( 20 to 59 years old) and the elderly ( $>60$ years old) accounted for a high percentage of the total number of

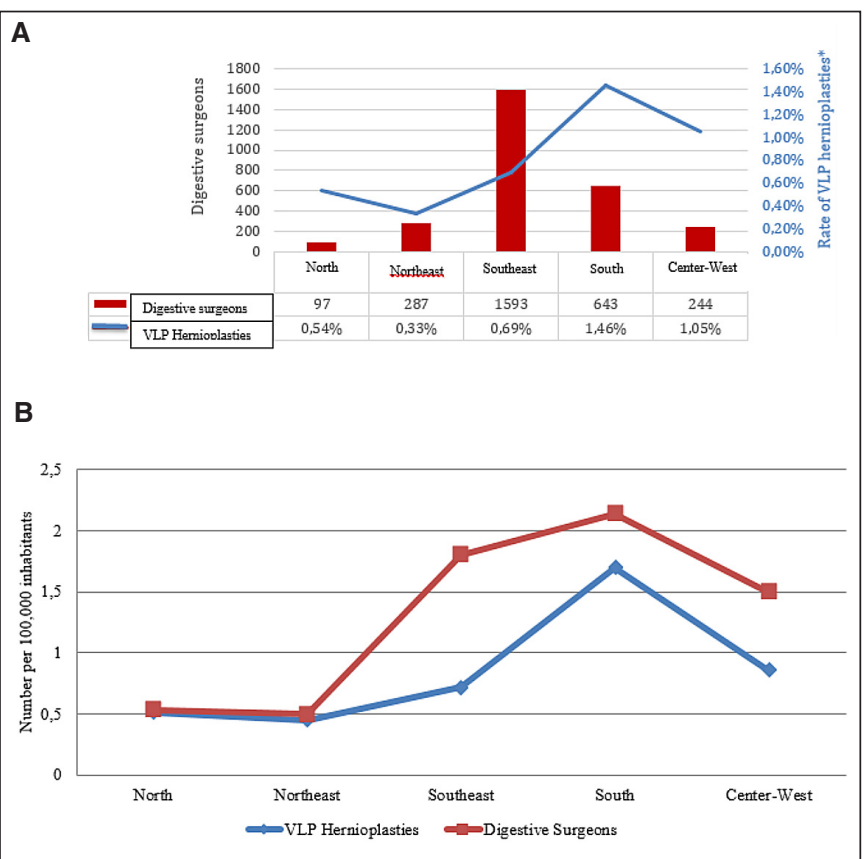

FIGURE 5. Association between laparoscopic hernioplasty and the number of digestive surgeons in 2018 by Brazilian region. * Percentages refer to the total number of hernioplasties performed in the evaluated period. A) Distribution of digestive surgeons in Brazilian regions and the percentage of laparoscopic surgeries performed in 2018. B) Number of laparoscopic hernioplasties and digestive surgeons per 100,000 inhabitants, in 2018 , by region.

notifications, $54.5 \%$, and $22.8 \%$, respectively. It contrasts with data from other population bases, in which there is usually a bimodal distribution pattern, with predominance in early childhood and the older population ${ }^{(17,19)}$. Caucasian individuals and browns predominated in the study, making up around $65 \%$ of all reported hernias, but with a high percentage of underreporting.

As a whole, it was demonstrated that in 11 consecutive years of observation, open surgeries of inguinal hernias showed a downward curve, with a decrease of approximately $19 \%$ in the number of inguinal hernioplasties between 2008 and 2017, with recovery only in the last year. The annual rate of inguinal hernioplasty was 64.6 per 100,000 inhabitants. In regions such as Northern Italy, this ratio is 340 per 100,000 inhabitants ${ }^{(18)}$, a ratio of 5 to 1 in relation to Brazil. When compared to other reference countries, such as Denmark, which is the only country with compulsory hernia registration, and corrected by the population, we observe that for every 100 inguinal hernia repairs in that country, Brazil performs $39^{(19)}$. However, when compared to South Korea, the Asian country performs a slightly larger number each year (100 vs 95.2) ${ }^{(17)}$. Open epigastric hernioplasties also show a tendency to decrease in the period, in contrast to open umbilical hernioplasties, which showed a progressive annual increase, more pronounced in the last year evaluated $(18 \%)$.

Laparoscopic surgeries to correct inguinal hernia showed oscillation in the first half of the period, with a tendency for slight growth in the last four years of the series. The other laparoscopic hernioplasties showed oscillations and were performed in a much lower number, showing that they are restricted to a smaller number of centers. The reduction in the number of open surgeries was 
not related to a compensatory increase in laparoscopic surgeries. Thus, the data demonstrate that there was a movement towards a progressive reduction in the number of surgeries. This impoundment puts pressure on the system and can have direct and indirect consequences since it allows an increase in the number of complications that require urgent surgical correction, which, in turn, determines increased costs, morbidity and mortality, physical and psychological suffering, and days off work. In a country with continental dimensions like Brazil, there is a dilution of these effects, but the impact should be an alert to health managers. It was found that the proportion of urgent surgeries in comparison to the total surgeries performed reached a significant value. Inguinal hernias, which represent the largest number, reached $22.1 \%$. Compared to other population studies, such as Sweden, the number of emergency surgeries in Brazil is almost four times higher ${ }^{(21)}$. In line with other reports, we observed in our sample that mortality from urgent surgeries was significantly higher compared to elective surgeries, having the most significant impact when there was a need for intestinal resection. It is known that urgent hernia surgery is more frequent in the elderly and increases mortality by six to nine times in relation to the general mortality of the population and 20 times if there is a need for intestinal resection ${ }^{(22)}$. Also, authors have suggested that poorly symptomatic, elderly patients and those with an unfavorable clinical condition should have their hernia repaired soon in order to avoid the high mortality associated with an emergency repair, without an increase in perioperative mortality when compared to the mortality in the general population ${ }^{(22)}$. The high frequency of urgent surgeries demonstrates the system's difficulty in performing a sufficient number of hernioplasties electively and avoiding complications within a reasonable standard. This indicator has great value, as it can be a benchmark for the results of future actions to improve the system as a whole. We do not have data on the waiting time to repair a hernia by the public system. Still, it is estimated to be between 1 and 2 years, considering a referral to specialized consultation, planning, and surgical scheduling ${ }^{(23,24)}$.

When we analyze the proportion of open and laparoscopic hernias, the reality is that there is an abyss between the techniques $(99.4 \%$ vs $0.6 \%)$. There was an increase in surgeries for laparoscopic inguinal hernias in the period analyzed ( $46 \%$, from $0.28 \%$ to $0.41 \%$ of the procedures performed). However, it is little representative given the distance between the two techniques. These data contrast with those in the United States, in which the laparoscopic technique represents about $27 \%$ of the procedures performed ${ }^{(25)}$, and in South Korea, where there was an increase from $2.4 \%$ to $29.5 \%$ in laparoscopic repairs between 2007 and 2015, a population with full coverage by national health insurance ${ }^{(17)}$. Brazilian data are more similar to those of Italians, where the average rate of laparoscopic surgery for inguinal hernia is $1.5 \%$, with an increase from 1 to $2 \%$ over ten years, with $75 \%$ of surgeries performed in public hospitals ${ }^{(18)}$. Even with the benefits related to the early return to activities and the economic impact, there was no consistent movement in the Brazilian public system to increase minimally invasive surgeries in the period evaluated. At the same time, there are no published data in the private system. The latter covers approximately $22 \%$ of the population, according to the National Agency of Supplementary Health (ANS) ${ }^{(26)}$. The causes of this slow progression may be related to factors such as training difficulties, an established culture, and insufficient financial transfers. Concerning the payments for services provided by partner institutions, there is a discrepancy in financing since the costs of laparoscopic surgery are higher. Still, the transfer is lower than that of open surgeries, a reason to discourage the development of minimally invasive surgery. The data collected reveal the disparity between the regions and states of the Federation. In the present study, we used the rates of surgeries per 100,000 inhabitants as a more representative element of regional realities, and we found that surgeries by open technique had a homogeneous distribution throughout the territory. This shows that this technique is consolidated in the country. Videolaparoscopy, on the other hand, showed significant heterogeneity between states and regions. Even in regions whose socio-economic development, calculated by the MHDI (Municipal Human Development Index), is higher, such as the Southeast region, the percentage is below those of regions with lower rates, such as the Center-West region. Although regional economic development is believed to have a direct impact on the provision of public services, the data revealed that the distribution of laparoscopic surgeries in the regions has a close relationship with the number of professionals with specialized training in digestive surgery. This association was observed in all regions of the country, except for the Southeast region. Therefore, although the list of surgeons trained to perform laparoscopic hernioplasties in the Southeast is one of the best in the country, this did not translate into an improvement in local rates when the data were divided by the population. One possible explanation for the finding is that laparoscopic hernias continue to be performed only in the academic environment, without proper dissemination outside the largest urban centers, and that laparoscopic surgeries are preferred only in cases of recurrences or bilateral hernias, which are smaller in number. Another explanation concerns the coverage by the private system in this region, which has the best rates in the country $(25-30 \%)^{(26)}$, with a tendency for surgeons to choose this technique in the care of patients with private health plans. In the present study, we observed a significantly higher mortality rate in cases operated by the laparoscopic technique when compared to the open technique, particularly in epigastric and umbilical hernias. This finding may reflect the technical difficulty related to these procedures, which require further training, and also the clinical status of the patients. However, the higher mortality observed in elective laparoscopic inguinal hernioplasties when compared to open ones should be interpreted with caution due to the small number of deaths in relation to the amount and rates remarkably close to zero in both.

This study has several limitations. For example, it is known that laparoscopic surgeries are performed more frequently in reference services, often found in capitals or regional centers. Still, these data are not available for comparative evaluation between cities in the countryside and those in the capitals. We do not have data to evaluate recurrent and bilateral hernias, in which laparoscopic surgery is one of the chosen techniques. Also, the data provided do not allow comparison of postoperative outcomes, such as rates of recurrence, infection, or bleeding, and time to return to work activities.

\section{CONCLUSION}

This study reports for the first time the population data of hernia surgeries in Brazil and maps the needs for actions and investments in different regions of the country. It was identified that the percentage of urgent surgeries reaches high levels, demonstrating the system's difficulties in avoiding complications. The data revealed heterogeneity in the distribution of laparoscopic procedures between regions and states, showing a direct relationship 
with the number of professionals with specialized training in digestive surgery. The data allow professionals and managers involved in the treatment of hernias with guidance on the formulation of health policies and awareness of the need to intensify efforts and develop strategies to improve health care coverage for the population dependent on the public system.

\section{Authors' contribution}

Everling EM, Tonatto-Filho AJ and Grezzana-Filho TJM designed the study. Everling EM, Gallotti FM and Tonatto-Filho AJ collected data. Everling EM and Bandeira DS processed the experimental data, performed the analysis, drafted the manuscript and designed the figures and tables. Bossardi $\mathrm{P}$ assisted with the interpretation of the results. Grezzana-Filho TJM directed and supervised the work. All authors discussed the results and commented on the manuscript.

\section{Orcid}

Eduardo Morais Everling:0000-0002-1033-3031.

Daniela Santos Bandeira: 0000-0001-6850-5767.

Felipe Melloto Gallotti: 0000-0001-9125-7407.

Priscila Bossardi: 0000-0003-1805-7120.

Antoninho José Tonatto-Filho: 0000-0002-4752-398X.

Tomaz de Jesus Maria Grezzana-Filho: 0000-0002-8597-4343.

Everling EM, Bandeira DS, Gallotti FM, Bossardi P, Tonatto-Filho AJ, Grezzana-Filho TJM. Reparo das hérnias abertas e laparoscópicas no Sistema Público de Saúde brasileiro. Estudo nacional baseado em dados populacionais em período de 11 anos. Arq Gastroenterol. 2020;57(4):484-90.

RESUMO - Contexto - Hérnias de parede abdominal são patologias cirúrgicas frequentes. O surgimento da cirurgia minimamente invasiva levantou questionamentos sobre a melhor técnica a ser aplicada, considerando a possível redução de dor pós-operatória e de complicações, e retorno precoce às atividades habituais. Objetivo - Avaliar frequência de hernioplastias abertas e laparoscópicas no Brasil entre os anos de 2008 e 2018, analisar taxas de cirurgias urgentes e eletivas, mortalidade, custos e o impacto do treinamento em cirurgia laparoscópica no sistema público de saúde. Métodos - Análise de banco de dados do registro de saúde pública (DATASUS) entre 2008 e 2018 para coleta dos dados e parâmetros selecionados. Resultados - Foram realizadas 2.671.347 hernioplastias no período, média de 242.850 cirurgias/ano ( $99,4 \%$ abertas, 0,6\% laparoscópicas). Predominou a faixa etária economicamente ativa (20-59 anos), 54,5\% do total. Houve redução significativa das cirurgias abertas $(P<0,01)$, sem aumento compensatório da laparoscopia. 22,3\% das cirurgias foram de urgência, com aumento significativo da mortalidade em relação às cirurgias eletivas $(P<0,01)$. Observou-se distribuição heterogênea da videolaparoscopia, diretamente relacionada com o número de cirurgiões digestivos. Conclusão - Este estudo apresenta pela primeira vez os dados populacionais das cirurgias de hérnia no Brasil. As técnicas minimamente invasivas representam uma parcela pouco significativa das hernioplastias. As cirurgias urgentes apresentam percentual elevado comparado a outros países, com aumento significativo na mortalidade, reforçando a necessidade de políticas que permitam aumento da oferta do serviço, treinamento especializado e equalização na distribuição dos procedimentos em todas as regiões.

DESCRITORES - Hérnia. Herniorrafia, métodos. Laparoscopia. Estudos populacionais em saúde pública.

\section{REFERENCES}

1. Miserez M, Alexandre JH, Campanelli G, Corcione F, Cuccurullo D, Pascual $\mathrm{MH}$, et al. The European hernia society groin hernia classification: Simple and easy to remember. Hernia. 2007;11:113-6. doi:10.1007/s10029-007-0198-3

2. Muysoms FE, Miserez M, Berrevoet F, Campanelli G, Champault GG, Chelala $\mathrm{E}$, et al. Classification of primary and incisional abdominal wall hernias. Hernia. 2009;13:407-14. doi:10.1007/s10029-009-0518-x

3. Brasil. Ministério da Saúde. DATASUS: Morbidade hospitalar do SUS. [Internet]. [Access 2020 April 8]. Available from https://datasus.saude.gov.br/acesso-a-informacao/morbidade-hospitalar-do-sus-sih-sus

4. Teixeira FMC, Pires FPA de A, Lima J de SF, Pereira FLDC, Silva CDA, Paula MHS, et al. Estudo de revisão da cirurgia de hernioplastia inguinal: técnica de Lichtenstein versus laparoscópica. Rev Médica Minas Gerais. 2017;27 (e-1860):44-51.

5. Muysoms FE, Antoniou SA, Bury K, Campanelli G, Conze J, Cuccurullo D, et al. European Hernia Society guidelines on the closure of abdominal wall incisions. Hernia. 2015;19:1-24. https://doi.org/10.1007/s10029-014-1342-5

6. Danzig MR, Stey AM, Yin SS, Qiu S, Divino CM. Patient profiles and outcomes following repair of irreducible and reducible Ventral Wall Hernias. Hernia 2016;20:239-47. doi:10.1007/s10029-015-1381-6

7. Goodenough CJ, Ko TC, Kao LS, Nguyen MT, Holihan JL, Alawadi Z, et al. Development and validation of a risk stratification score for ventral incisiona hernia after abdominal surgery: Hernia expectation rates in intra-abdominal surgery (The HERNIA project). J Am Coll Surg. 2015;220:405-13. doi:10.1016/j. jamcollsurg.2014.12.027

8. Kaoutzanis C, Leichtle SW, Mouawad NJ, Welch KB, Lampman RM, Wahl WL, et al. Risk factors for postoperative wound infections and prolonged hospitalization after ventral/incisional hernia repair. Hernia. 2015;19:113-23. doi:10.1007/ s10029-013-1155-y
9. Holihan JL, Hannon C, Goodenough C, Flores-Gonzalez JR, Itani KM, Olavarria O, et al. Ventral Hernia Repair: A Meta-Analysis of Randomized Controlled Trials. SurgInfect (Larchmt). 2017;18:647-58. doi:10.1089/sur.2017.029

10. Savitch SL, Shah PC. Closing the gap between the laparoscopic and open approaches to abdominal wall hernia repair: a trend and outcomes analysis of the ACS-NSQIP database. SurgEndosc. 2016;30:3267-78. doi:10.1007/s00464-0154650-7

11. Zhang Y, Zhou H, Chai Y, Cao C, Jin K, Hu Z. Laparoscopic versus open incisional and ventral hernia repair: A systematic review and meta-analysis. World J Surg. 2014;38:2233-40. doi:10.1007/s00268-014-2578-z

12. Ministério da Saúde do Brasil. DATASUS: Procedimentos hospitalares do SUS por local de internação. [Internet]. [Access 2020 Mar 3]. Available from http:// tabnet.datasus. gov.br/cgi/deftohtm.exe?sih/cnv/qiuf.def.

13. Ministério da Saúde do Brasil. SIGTAP - Sistema de Gerenciamento da Tabela de Procedimentos, Medicamentos e OPM do SUS. [Internet]. [Access 2020 Jun 2]. Available from http://sigtap.datasus.gov.br/tabela-unificada/app/sec/inicio.jsp

14. Rutkow IM. Demographic and socioeconomic aspects of hernia repair in the United States in 2003. SurgClin North Am. 2003;83:1045-51. doi:10.1016/S00396109(03)00132-4

15. Primatesta $\mathrm{P}$, Goldacre, MJ. Inguinal hernia repair: incidence of elective and emergency surgery, readmission and mortality. International Journal of Epidemiology. 1996;25:835-9.

16. Zendejas B, Ramirez T, Jones T, Kuchena A, Martinez J, Ali SM, et al. Trends in the utilization of inguinal hernia repair techniques: a population-based study. The American Journal of Surgery. 2012;203:313-7.

17. Han SR, Kim HJ, Kim NH, Shin S, Yoo RN, Kim G, et al. Inguinal hernia surgery in Korea: nationwide data from 2007-2015. Annals of surgical treatment and research. 2019;97:41-7. 
18. Ansaloni L, Coccolini F, Fortuna D, Catena F, Di Saverio S, Belotti LMB, et al Assessment of 126,913 inguinal hernia repairs in the Emilia-Romagna region of Italy: analysis of 10 years. Hernia. 2014;18:261-7.

19. Burcharth J, Pedersen M, Bisgaard T, Pedersen C, Rosenberg J. Nationwide prevalence of groin hernia repair. PLoS One. 2013;8:e54367. doi: 10.1371/journal. pone.0054367.

20. Akin ML, Karakaya M, Batkin A, Nogay A. Prevalence of inguinal hernia in otherwise healthy males of 20 to 22 years of age. J R Army Med Corps. 1997; 143:101-2.

21. Koch A, Edwards A, Haapaniemi S, Nordin P, Kald A. Prospective evaluation of 6895 groin hernia repairs in women. Br J Surg. 2005;92:1553-8. doi:10.1002/ bjs. 5156

22. Nilsson H, Stylianidis G, Haapamäki M, Nilsson E, Nordin P. Mortality after groin hernia surgery. Ann Surg. 2007;245:656-60. doi: 10.1097/01 sla.0000251364.32698.4b.
23. Conselho Federal de Medicina. Crise no SUS: Brasil tem mais de 900 mil cirurgias eletivas represadas. 2017. [Internet]. [Access 2020 Jun 2]. Available from https://portal.cfm.org.br/index.php?option=com_content\&view=article\&id=27314:crise-no-sus-brasil-tem-mais-de-900-mil-cirurgias-eletivas-represadas\&catid $=3$

24. Neto A. Cirurgia do SUS com maior tempo de espera em Porto Alegre demora mais de 670 dias. 2019. [Internet]. [Access 2020 Jun 2]. Available from https://gauchazh.clicrbs.com.br/porto-alegre/noticia/2019/01/cirurgia-dosus-com-maior-tempo-de-espera-em-porto-alegre-demora-mais-de-670-diascjqhr1v53014w01nvse9wg7zo.html

25. Funk LM, Perry KA, Narula VK, Mikami DJ, Melvin WS. Current national practice patterns for inpatient management of ventral abdominal wall hernia in the United States. Surg Endosc. 2013;27:4104-4112. doi:10.1007/s00464-013-3075-4

26. Agência Nacional de Saúde Suplementar [Internet]. [Access 2020 Jun 2]. Available from http://www.ans.gov.br/perfil-do-setor/dados-gerais 